\title{
Incubadoras tecnológicas de cooperativas populares: realidade da incubação de empreendimentos econômicos solidários com participação de usuários de serviços de saúde mental
}

\author{
Technological incubators of popular cooperatives: reality \\ of the incubation of solidarity economy enterprises with the \\ participation of users of mental health services
}

\author{
Isabela Aparecida de Oliveira Lussi ${ }^{1}$, Léia de Andrade Tessarini ${ }^{2}$, \\ Giovana Garcia Morato ${ }^{3}$
}

http://dx.doi.org/10.11606/issn.2238-6149.v26i3p345-354

\begin{abstract}
Lussi IAO, Tessarini LA, Morato GG. Incubadoras tecnológicas de cooperativas populares: realidade da incubação de empreendimentos econômicos solidários com participação de usuários de serviços de saúde mental. Rev Ter Ocup Univ São Paulo. 2015 set.-dez.;26(3):345-54.
\end{abstract}

RESUMO: As Incubadoras Tecnológicas de Cooperativas Populares (ITCPs) são organizações vinculadas às universidades que têm papel importante no desenvolvimento da Economia Solidária. Com o surgimento da reabilitação psicossocial, os empreendimentos econômicos solidários (EES) tornaram-se uma alternativa de inserção social pelo trabalho para usuários de serviços de saúde mental. A presente pesquisa objetivou investigar quais ITCPs estão incubando EES que contam com a participação destes usuários, caracterizar esses empreendimentos e identificar as principais demandas, desafios, dificuldades e oportunidades encontradas no processo de incubação de tais empreendimentos. Trata-se de estudo qualitativo que teve participação de 4 profissionais responsáveis pela incubação dos EES vinculados a 3 ITCPs. Os resultados apontaram que as demandas, os desafios, as dificuldades e as oportunidades relacionam-se principalmente com: o exercício da autogestão; os processos de produção; a interferência das subjetividades dos participantes dos EES no trabalho coletivo e aos apoios e parcerias. As intervenções dos técnicos de incubação se mostraram essenciais para a possível resolubilidade das dificuldades e aproveitamento das facilidades para efetivar a reabilitação psicossocial dos usuários.

DESCRITORES: Reabilitação; Trabalho/economia; Saúde mental.
Lussi IAO, Tessarini LA, Morato GG. Technological incubators of popular cooperatives: reality of the incubation of solidarity economy enterprises with the participation of users of mental health services. Rev Ter Ocup Univ São Paulo. 2015 Sept.Dec.;26(3):345-54.

\begin{abstract}
Technological incubators of popular cooperatives (ITCP - Incubadoras Tecnológicas de Cooperativas Populares) are organizations that are linked to universities and have an important role in the development of Solidarity Economy. With the rise of psychosocial rehabilitation, solidarity economy enterprises (Empreendimentos Econômicos Solidários - EES) became an alternative for mental health service users to be socially included. This study aimed at investigating which ITCPs are incubating EES with the participation of those users, at characterizing such ventures, and at identifying the main demands, challenges, difficulties, and opportunities that were found in the incubation process of such enterprises. It is a qualitative study that had 4 professionals in charge of the incubation of the EES linked to 3 ITCPs. The results pointed out that the demands, challenges, difficulties, and opportunities mainly relate to exercising self-management; production processes; interference from EES members' subjectivities in the collective work and to support initiatives and partnerships. The interventions from the incubation technicians were found to be essential to solve problems and to make the most of the facilities to achieve the users' psychosocial rehabilitation.
\end{abstract}

KEYWORDS: Rehabilitation; Work/economy; Mental health.

O presente artigo é oriundo de pesquisa de Iniciação Científica.

1. Universidade Federal de São Carlos - UFSCar, Departamento de Terapia Ocupacional, Programa de Pós-Graduação em Terapia Ocupacional, Núcleo Multidisciplinar e Integrado de Estudos, Formação e Intervenção em Economia Solidária (NuMI-EcoSol) de São Carlos-UFSCar. Bolsista do CNPq - Brasil. E-mail: bellussi@ufscar.br.

2. Fundação Faculdade de Medicina (FFM), Projeto CAPE - Centro de Apoio Pedagógico Especializado. E-mail: 1tessarini@hotmail.com

3. Universidade Federal de São Carlos - UFSCar, Departamento de Terapia Ocupacional. E-mail: giovana_morato@hotmail.com.

Endereço para correspondência: Departamento de Terapia Ocupacional da UFSCar. Rod. Washington Luís, km 235. São Carlos, SP, Brasil. CEP: 13565-905. E-mail: bellussi@ufscar.br. 


\section{INTRODUÇÃO}

$\Lambda \begin{aligned} & \text { s Incubadoras Tecnológicas de Cooperativas } \\ & \text { Populares (ITCPs) são organizações } \\ & \text { vinculadas às universidades que objetivam }\end{aligned}$ a utilização dos recursos humanos destas e o conhecimento nelas produzido para a formação, qualificação e assessoria de trabalhadores no desenvolvimento de empreendimentos autogestionários tendo começado a surgir em razão da crescente demanda dos trabalhadores pela formação destes empreendimentos ${ }^{1,2}$. Nesse sentido, em meados de 1990 iniciou-se o programa da Incubadora Tecnológica de Cooperativas Populares da Universidade Federal do Rio de Janeiro - pioneira neste percurso e precursora de várias outras Incubadoras Universitárias no contexto nacional ${ }^{3}$.

A atuação dessas incubadoras universitárias alcança diversos atores sociais e múltiplas dimensões. As ações de maior destaque são aquelas relacionadas à incubação de empreendimentos, ao fortalecimento do movimento da economia solidária (por meio da construção de redes e fóruns em diversas instâncias da sociedade civil e do Estado), à maior representatividade política e ao desenvolvimento sustentável de base local ou regional ${ }^{4}$.

Destaca-se que, além da extensão, as ITCPs também se comprometem com as atividades de ensino e pesquisa, fundamentais para formar quadros de profissionais para atuarem nos próprios empreendimentos ou nas entidades de apoio à economia solidária 5 .

As cooperativas incubadas pelas ITCPs se fundamentam nos princípios da economia solidária, cujas características são:

posse coletiva dos meios de produção pelas pessoas que a utilizam para produzir; gestão democrática da empresa ou por participação direta (quando o número de cooperadores não é demasiado) ou por representação; repartição da receita líquida entre os cooperadores por critérios aprovados após discussões e negociações entre todos; destinação do excedente anual (denominado "sobras") também por critérios acertados entre todos os cooperadores (p.13) ${ }^{6}$.

Embora opere numa lógica contrária ao capitalismo e difunda um modelo de produção mais humano e solidário, por vezes, a prática da economia solidária se torna difícil e em algumas circunstâncias, inviável.

Mediante as possíveis dificuldades que uma cooperativa pode apresentar, as incubadoras agem como um importante instrumento de auxílio buscando maneiras e estratégias de contornarem os principais desafios. Para tanto, as ITCPs se propõem a fornecer capacitação à população, sobretudo a quem vive precariamente ou está desempregado, por exemplo, abordando o cooperativismo e a área profissional escolhida ${ }^{7}$.

No cenário nacional as ITCPs se organizaram em redes a fim de potencializar ainda mais a economia solidária no país. São elas, a Rede Universitária de Incubadoras Tecnológicas de Cooperativas Populares (Rede de ITCPs) e a Unitrabalho.

Os desafios de incubação são variados. São diferentes os problemas apresentados pela população, os recursos disponíveis para efetuar os processos de incubação e demandas específicas de cada empreendimento. Nessa direção, os desafios presentes nos empreendimentos econômicos solidários (EES) com participação de usuários de serviços de saúde mental (USSM) também buscam ações efetivas que as incubadoras podem proporcionar. A união dessa população aos moldes solidários de economia é atual e merece atenção apropriada para que haja resolutividade e eficácia das ações ${ }^{8}$.

As redefinições de conhecimento e atuação na área da saúde mental advindas do processo de reforma psiquiátrica permitiram o surgimento de um novo campo de estudo, reflexão e prática dentro dessa temática: a reabilitação psicossocial ${ }^{9}$, que pressupõe que o indivíduo exerça a cidadania e estabeleça contratualidade em três esferas de sua vida, sendo uma delas o trabalho ${ }^{10}$. Portanto, o movimento da reforma psiquiátrica brasileiro, ao adotar a reabilitação psicossocial como modelo, afirma a importância da discussão do trabalho como direito e como orientador da vida destes sujeitos ${ }^{11}$.

Nesse sentido, os EES podem servir de dispositivos de reabilitação psicossocial, pois a inclusão proporcionada pelos mesmos faz com que os USSM não sejam vistos ou não se reconheçam como uma pessoa que apresenta determinado tipo de transtorno, mas como um trabalhador que tem a oportunidade de desenvolver seu potencial social assumindo responsabilidades, estabelecendo relações, criando vínculos com a equipe e outros trabalhadores. Isso se deve às várias implicações do fazer parte de um grupo de geração de renda: chegar ao local do empreendimento, cuidar do dinheiro e vendas, participar das assembleias, tomar decisões, calcular sobras e dividi-las ${ }^{12}$.

Apesar de ser um dispositivo para a inserção social dos usuários, o trabalho desenvolvido nos EES que contam com a participação de USSM possui não apenas facilidades e benefícios, mas também dificuldades próprias de cada empreendimento e das pessoas que o compõem.

Diante do exposto e considerando que as ITCPs podem contribuir significativamente para a formação, desenvolvimento e consolidação dos EES formados por USSM, o presente estudo teve como objetivos: 
- Identificar quais ITCPs que compõem a Rede de ITCPs, estão incubando EES que contam com a participação de USSM e caracterizar esses empreendimentos;

- Identificar as principais demandas, desafios, dificuldades e oportunidades encontradas pelas equipes das ITCPs no processo de incubação desses empreendimentos.

\section{METODOLOGIA}

Trata-se de um estudo de abordagem qualitativa que utilizou três formulários para a coleta de dados.

O formulário 1 abordou os aspectos pessoais e profissionais dos sujeitos da pesquisa tais como idade, sexo, escolaridade, profissão e tempo de experiência em incubação de EES.

O formulário 2 buscou identificar e caracterizar os EES que contam com a participação de USSM do ponto de vista do tempo de existência do grupo, da sua composição (se formado somente por USSM ou por grupos mistos), da procedência (oriundos de serviços de saúde mental ou não), da dimensão (número de pessoas), da atividade desenvolvida, entre outros.

O formulário 3 objetivou identificar as principais demandas, desafios, dificuldades e oportunidades encontradas pelos EES que contam com a participação de USSM. Este questionário foi composto por questões semiestruturadas.

\section{Participantes}

Foram participantes do estudo 4 profissionais das incubadoras responsáveis pelo processo de incubação de EES que contam com a participação de USSM. Estes quatro profissionais pertencem às seguintes incubadoras: INCOOP/UFSCar (Incubadora Regional de Cooperativas Populares, antecessora do Núcleo Multidisciplinar e Integrado de Estudos, Formação e Intervenção em Economia Solidária - NuMI-EcoSol/UFSCar) ITCPFGV e ITCP-UFRGS; sendo dois sujeitos pertencentes à INCOOP/UFSCar.

\section{Coleta de dados}

Antes do início do desenvolvimento da pesquisa, o projeto foi encaminhado ao Comitê de Ética em Pesquisa em Seres Humanos sendo aprovado sob o protocolo: $\mathrm{n}^{\circ}$ 0231.0.135.000-11. Somente após sua aprovação a coleta de dados foi iniciada, em janeiro de 2012, e finalizada no mês seguinte.

A identificação das ITCPs se deu por meio de uma lista de todas as ITCPs que compõem a Rede disponível, à época, no site da Rede. O contato com as ITCPs foi feito por meio de acesso a páginas da internet se valendo do auxílio de sites de pesquisa. Além dessas páginas, as ITCPs inicialmente acionadas também forneceram contato de outras ITCPs. A princípio, os contatos foram feitos por meio de telefonemas com todas as incubadoras que compõem a Rede de ITCPs. Posteriormente, às incubadoras cujo contato telefônico não foi efetivado, foram enviadas mensagens aos endereços eletrônicos.

Ao todo, 44 ITCPs foram identificadas. Desse total, 24 contatos foram realizados por meio de telefonemas e 12 por mensagens enviadas ao correio eletrônico; nas oito restantes, os contatos telefônicos não tiveram sucesso e as mensagens enviadas não foram respondidas.

Por meio dos contatos realizados constatou-se que o número de incubadoras que possuem EES que contam com a participação de USSM eram nove. Destas, o contato se efetivou apenas com oito. A partir destes, identificou-se nove profissionais responsáveis pela incubação dos EES em questão, sendo dois deles pertencentes a uma mesma incubadora, porém trabalhando em dois EES diferentes com participação de USSM. Desses nove profissionais, apenas quatro responderam aos formulários, assinaram o Termo de Consentimento Livre e Esclarecido e os enviaram por correio eletrônico aos pesquisadores. Os cinco demais não mantiveram correspondência.

Portanto, o número final de participantes foi quatro, vinculados a três ITCPs.

\section{Análise dos dados}

Os dados coletados por meio dos formulários 1 e 2 foram analisados de maneira descritiva e o conteúdo das repostas apresentadas no formulário 3 , foi submetido à Técnica de Análise Temática ${ }^{13}$.

\section{RESULTADOS E DISCUSSÃO}

Dos dados oriundos dos formulários foi possível a identificação de três categorias, sendo que na terceira encontraram-se quatro subcategorias. São elas:

- Caracterização dos participantes da pesquisa;

- Identificação e caracterização dos EES que contam com a participação de USSM;

- Identificação das principais demandas, desafios, dificuldades e oportunidades dos EES que contam 
com participação de USSM:

- Exercício da autogestão;

- Processos de produção;

- A interferência das subjetividades dos participantes dos EES no trabalho coletivo;

- Apoios e parcerias.

\section{Caracterização dos participantes da pesquisa}

De acordo com a Tabela 1 os participantes se distribuem igualmente quanto ao gênero e estado civil, três deles têm a mesma carga horária de trabalho e apresentam uma situação bem diferenciada em relação à profissão, à formação profissional e ao tempo de trabalho na incubadora.

Tabela 1 - Caracterização dos participantes

\begin{tabular}{|c|c|c|c|c|}
\hline $\begin{array}{l}\text { Participantes/Dados } \\
\text { de identificação }\end{array}$ & Participante 1 & Participante 2 & Participante 3 & Participante 4 \\
\hline Idade & 23 & 27 & 30 & 51 \\
\hline Gênero & Feminino & Masculino & Feminino & Masculino \\
\hline Estado Civil & Solteira & Solteiro & Casada & Casado \\
\hline Profissão & $\begin{array}{l}\text { Coordenadora } \\
\text { executiva na ITCP. }\end{array}$ & $\begin{array}{l}\text { Coordenador técnico de } \\
\text { projetos em Economia } \\
\text { Solidária }\end{array}$ & Técnica de incubação & $\begin{array}{l}\text { Funcionário Público } \\
\text { Federal }\end{array}$ \\
\hline Formação Profissional & $\begin{array}{l}\text { Graduação em } \\
\text { Enfermagem concluída } \\
\text { em } 2011 \text {. }\end{array}$ & $\begin{array}{l}\text { Graduação em Ciências } \\
\text { Biológicas concluída } \\
\text { em } 2008 .\end{array}$ & $\begin{array}{l}\text { Graduação em Engenharia } \\
\text { Química concluída } \\
\text { em 2005, Mestrado } \\
\text { (Programa: Ciências e } \\
\text { Engenharia do Petróleo, } \\
\text { Área de Concentração: } \\
\text { Explotação, concluído em } \\
\text { 2008). }\end{array}$ & $\begin{array}{l}\text { Licenciatura em História } \\
\text { e Geografia, Mestrado } \\
\text { em Geografia/Território } \\
\text { concluído em } 2011 \text {. }\end{array}$ \\
\hline $\begin{array}{l}\text { Tempo de trabalho na } \\
\text { atual incubadora }\end{array}$ & 6 meses & 2 anos e 5 meses & 1 ano e 5 meses & 12 anos \\
\hline Carga horária semanal & 20 horas & 40 horas & 40 horas & 40 horas \\
\hline
\end{tabular}

É possível observar que a profissão apontada pelos participantes e que se refere às responsabilidades de incubação são relatadas com identificações distintas e apenas um dos participantes menciona uma profissão diferente: funcionário público federal. Estes dados refletem a situação atual da grande maioria das ITCPs, as quais têm suas equipes compostas por docentes, poucos técnicos administrativos, alunos de graduação e pós-graduação e coordenadores técnicos de incubação contratados com recursos provenientes de projetos de intervenção e pesquisa submetidos em editais públicos.

Se por um lado a contratação de técnicos de incubação é benéfica, pois viabiliza a assessoria constante aos EES incubados pelas ITCPs, por outro, a fragilidade dos contratos dos mesmos, que são sempre determinados pelo tempo de execução de cada projeto, prejudica a continuidade das ações das ITCPs.

Em relação à formação profissional, os sujeitos se distinguem pela pluralidade das graduações e áreas das pós-graduações, no caso os cursos de mestrado, realizados por dois deles.

Quanto ao tempo de trabalho na atual ITCP, os resultados são bem diversificados, sendo que entre o menor e o maior tempo de contratação existe uma diferença de 11 anos e 6 meses. Sobre a jornada de trabalho semanal dos sujeitos, apenas um trabalha 20 horas semanais e todos os outros têm a mesma carga horária.

Participação em reuniões, processos de gestão administrativa e participações comunitárias foram as ações relatadas por mais de um participante como mostra a Tabela 2. As participações em fóruns e em eventos que abrangem a temática de economia solidária e ITCPs também são papéis dos responsáveis pelo processo de incubação e são importantes para troca de conhecimento, estabelecimento de parcerias, discussão de problemas. 
Lussi IAO et al. Incubadoras tecnológicas de cooperativas populares. Rev Ter Ocup Univ São Paulo. 2015 set.-dez.;26(3):345-54.

Tabela 2 - Atividades desenvolvidas

\begin{tabular}{|c|c|c|}
\hline $\begin{array}{l}\text { Participante/ } \\
\text { Atividades }\end{array}$ & Atividades que desenvolve na incubadora & $\begin{array}{l}\text { Atividades que estão diretamente relacionadas ao(s) EES que } \\
\text { conta(m) com a participação de USSM }\end{array}$ \\
\hline Participante 1 & $\begin{array}{l}\text { Participação em reuniões da incubadora, elaboração } \\
\text { de relatórios, participação no Fórum Municipal de } \\
\text { Economia Solidária, atendimento de demandas da } \\
\text { incubadora (responder e-mails, resolver problemas), } \\
\text { organização de eventos da incubadora }\end{array}$ & $\begin{array}{l}\text { planejamento de atividades no empreendimento, participação em } \\
\text { assembleias, formação em economia solidária e temas relacionados, } \\
\text { atendimento de demandas do empreendimento juntamente com } \\
\text { os sócios. }\end{array}$ \\
\hline Participante 2 & $\begin{array}{l}\text { Coordenação técnica envolvendo: planejamento e } \\
\text { realização de reuniões, coordenação de trabalhos dos } \\
\text { bolsistas, representação em atividades gerais; } \\
\text { Gestão operacional e financeira de Projetos; } \\
\text { Elaboração de relatórios periódicos para órgãos } \\
\text { financiadores; } \\
\text { Participação no Fórum Municipal de Economia } \\
\text { Solidária; } \\
\text { Apoio ao Banco Comunitário; } \\
\text { Articulação e manutenção das parcerias com espaços } \\
\text { sociais do município; } \\
\text { Participação em reuniões gerais semanais; } \\
\text { Mobilização comunitária para a formação de um EES } \\
\text { de produção de alimentos no território. }\end{array}$ & $\begin{array}{l}\text { Acompanhamento do Grupo Horta, que consiste em: } \\
\text { Participação durante os encontros de todos os membros do grupo; } \\
\text { Motivação dos membros para que não abandonem o projeto e gestão } \\
\text { de conflitos que surgem no convívio entre os membros; } \\
\text { Capacitação dos membros para a autogestão da Horta; } \\
\text { Capacitação técnica para a produção de hortaliças orgânicas; } \\
\text { Identificação de moradores do território com interesse em participar } \\
\text { do Grupo; } \\
\text { Articulação com a coordenação do Centro da Juventude } \\
\text { para manutenção da parceria e da cessão do terreno para o } \\
\text { desenvolvimento da Horta; } \\
\text { Identificação e esforço para envolver os bolsistas na equipe. }\end{array}$ \\
\hline Participante 3 & $\begin{array}{l}\text { Incubação de empreendimentos no seguimento de } \\
\text { produtos de limpeza e resíduos sólidos. }\end{array}$ & Incubação de EES de produtos de limpeza \\
\hline Participante 4 & $\begin{array}{l}\text { Gerência administrativa; } \\
\text { Incubação de EES/Formador de formadores/ } \\
\text { Coordenação de Área. }\end{array}$ & $\begin{array}{l}\text { Acompanhamento de atividades de incubação; } \\
\text { Assessoria junto à GerAÇÃO-POA (órgão público que coordena } \\
\text { atividades junto aos usuários), } \\
\text { Formação da Associação de Usuários de serviços Saúde Mental; } \\
\text { Participação em fóruns relacionados ao tema. }\end{array}$ \\
\hline
\end{tabular}

Observa-se um esforço dos participantes para que os EES alcancem a autogestão.

Aparece ainda, um singular elemento, o esforço pessoal do profissional, demonstrado pela busca de motivação dos membros para que não abandonem o projeto devido a problemas pessoais; gestão de conflitos que surgem no convívio entre os membros e busca pela identificação e esforço para envolvimento de bolsistas na equipe.

\section{Identificação e caracterização dos EES que contam com a participação de USSM}

A Tabela 3 aponta para um dado interessante, um único empreendimento é constituído por apenas USSM, os outros EES são formados por grupos mistos, ou seja, usuários e outras pessoas que não se encontram nesta condição. 
Lussi IAO, et al. Incubadoras tecnológicas de cooperativas populares. Rev Ter Ocup Univ São Paulo. 2015 set.-dez.;26(3):345-54.

Tabela 3 - Caracterização dos EES com participação de USSM

\begin{tabular}{|c|c|c|c|c|}
\hline Características/ITCPs & \multicolumn{2}{|c|}{ INCOOP/UFSCar } & ITCP-FGV & ITCP-UFRGS \\
\hline $\begin{array}{l}\text { Nome do(s) EES que contam } \\
\text { com a participação de usuários }\end{array}$ & Recriart & $\begin{array}{l}\text { Horta } \\
\text { Comunitária } \\
\text { do Centro da } \\
\text { Juventude }\end{array}$ & Limpet Valongo & GerAÇÃO/POA \\
\hline $\begin{array}{l}\text { Número de participantes no } \\
\text { EES }\end{array}$ & 15 & 05 & 12 & 34 \\
\hline $\begin{array}{l}\text { Número de usuários de saúde } \\
\text { mental no EES }\end{array}$ & 15 & 01 & 02 & 04 \\
\hline Procedência dos usuários & $\begin{array}{l}\text { Centro de Atenção } \\
\text { Psicossocial (CAPS) }\end{array}$ & $\begin{array}{l}\text { Unidade de } \\
\text { Saúde da Família } \\
\text { (USF) }\end{array}$ & $\begin{array}{l}\text { Centro de } \\
\text { Atenção } \\
\text { Psicossocial } \\
\text { (CAPS) }\end{array}$ & $\begin{array}{l}\text { Centro de Atenção Psicossocial } \\
\text { (CAPS), ambulatórios e atenção } \\
\text { primária (USF e Unidade Básica de } \\
\text { Saúde) }\end{array}$ \\
\hline $\begin{array}{l}\text { Carga horária de } \\
\text { funcionamento dos EES }\end{array}$ & 10 horas semanais & 9 horas diárias & $\begin{array}{l}20 \text { horas } \\
\text { semanais }\end{array}$ & 50 horas semanais \\
\hline Atividades realizadas & $\begin{array}{l}\text { Produção de papel } \\
\text { reciclado e uso deste } \\
\text { para confecção de } \\
\text { produtos artesanais; } \\
\text { comercialização } \\
\text { desses produtos. }\end{array}$ & $\begin{array}{l}\text { Produção de } \\
\text { hortaliças } \\
\text { orgânicas para } \\
\text { consumo dos } \\
\text { membros e de sua } \\
\text { família. }\end{array}$ & $\begin{array}{l}\text { Produção de } \\
\text { vassouras de } \\
\text { garrafa pet }\end{array}$ & $\begin{array}{l}\text { Produção de papel reciclado, velas e } \\
\text { serigrafia. }\end{array}$ \\
\hline $\begin{array}{l}\text { Outros profissionais que atuam } \\
\text { no empreendimento além do } \\
\text { técnico de incubação }\end{array}$ & $\begin{array}{l}4 \text { auxiliares de } \\
\text { enfermagem, } 1 \\
\text { terapeuta ocupacional, } \\
1 \text { psicólogo e 1docente } \\
\text { do Departamento } \\
\text { de Enfermagem da } \\
\text { Universidade. }\end{array}$ & $\begin{array}{l}\text { Não possui outros } \\
\text { profissionais }\end{array}$ & $\begin{array}{l}\text { Não possui } \\
\text { outros } \\
\text { profissionais }\end{array}$ & $\begin{array}{l}\text { Profissionais ligados à área das artes, } \\
\text { design. Outros profissionais podem } \\
\text { atuar de acordo com a demanda }\end{array}$ \\
\hline Tempo de existência & 6 anos & 2 anos e 8 meses & 7 anos & 10 anos \\
\hline $\begin{array}{l}\text { Valor médio mensal das } \\
\text { retiradas }\end{array}$ & 50 reais & $\begin{array}{l}\text { Não existe } \\
\text { retirada em } \\
\text { dinheiro }\end{array}$ & 150 reais & 30 reais \\
\hline
\end{tabular}

Para Dakuzaku' ${ }^{14}$, as cooperativas de trabalho que contam com "populações especiais" (p.252) ${ }^{14}$ não devem se restringir a esta população, pois o convívio com pessoas que não se encontram nesta condição é propiciador de inclusão social. Nesse sentido, as cooperativas mistas parecem bastante positivas, pois permitem trocas de conhecimento, habilidades e a desconstrução de estigmas no cotidiano dos EES.

Em relação às retiradas, observou-se que na Horta
Comunitária, como apontado na Tabela, estas não existem, a produção é realizada em um terreno público onde a comercialização não está autorizada, a produção fica destinada ao consumo próprio e familiar.

Cabe salientar que as retiradas possuem um valor muito pequeno, o maior deles apresentado é muito inferior a um salário mínimo, o que configura a inclusão dos trabalhadores, do ponto de vista econômico, como incompleta já que a renda por meio dessa atividade não 
permite o suprimento de necessidades básicas. Relacionado a este aspecto, o trabalho de Tagliaferro ${ }^{12}$ questiona se o empreendimento que gera pouca renda constitui-se como trabalho ou como uma atividade qualquer que ocupe o tempo ocioso.

Aponta-se para a necessária discussão acerca deste aspecto e reflexões sobre estratégias para o enfrentamento desta condição, visto que um dos riscos destas iniciativas, quando não geram renda, é serem concebidas como oficinas terapêuticas ou meros espaços de entretenimento.

\section{Identificação das principais demandas, desafios, dificuldades e oportunidades dos EES que contam com participação de USSM}

O formulário 3 abordou diretamente a identificação das principais demandas, desafios, dificuldades e oportunidades dos EES.

A Análise Temática aplicada ao formulário permitiu a identificação de quatro subcategorias. Neste artigo serão apresentadas e discutidas, a seguir, apenas duas delas.

\section{Exercício da autogestão}

A autogestão é um exercício que envolve as habilidades, tanto dos membros dos EES quanto dos técnicos de incubação e/ou outros profissionais, para a participação em um coletivo que envolve: se colocar perante o grupo, opinar, aceitar e compreender outras opiniões; entender suficientemente o EES, sua proposta, suas demandas. São habilidades de caráter social que muitas vezes necessitam ser aprendidas.

Sobre o exercício da autogestão as respostas dos participantes evidenciaram desafios e possibilidades referentes à participação dos usuários nos EES.

Os desafios se relacionam com o aumento do grau de envolvimento e de participação dos usuários nas ações administrativas e gerenciais, ou seja, uma das exigências demonstradas na definição de autogestão descrita anteriormente para essa prática nos EES. O relato a seguir mostra o pouco envolvimento dos usuários em ações gerenciais e administrativas.

"Nenhum dos dois (usuários membros do EES) conseguiram se envolver nas atividades gerenciais e administrativas atribuidas entre os membros por enquanto" (P3).

Também foi apontada por um dos participantes a dificuldade dos usuários em assumirem atividades de gerenciamento, como mostra o depoimento a seguir.
"A proposta é de que os usuários protagonizem o gerenciamento e organização da produção, mas necessitam de auxílio inúmeras vezes" (P4).

A falta de envolvimento dos usuários em atividades gerenciais e a necessidade de auxílio na execução de ações de autogestão percebidas pelos participantes demonstram dificuldades para que o grupo avance neste processo, que é um importante princípio da economia solidária.

No trabalho de Tagliaferro ${ }^{12}$, esta mesma dificuldade foi evidenciada pelos membros da equipe que atuam com usuários do CAPS em um EES. A autora aponta que determinadas decisões de urgência foram tomadas pela equipe e levadas ao grupo posteriormente.

Percebe-se, portanto, que a participação dos usuários no processo da autogestão está aquém do ideal para a proposta da economia solidária.

Outro participante aborda a autogestão como um desafio, relacionando-a com a questão da produção:

"Alcançar um nivel de gestão da produção que possibilite uma produção constante e de qualidade ao longo de todo $o$ ano, tendo verduras a oferecer todos os dias" (P2).

Dados apresentados nos formulários apontaram ainda a existência de ações pensadas a princípio pelos técnicos de incubação que objetivaram estimular a autogestão nos EES. Algumas ações ou estratégias promoveram a melhora das demandas relacionadas, outras não demonstraram tanta eficiência. As possíveis razões citadas apontam a falta de continuidade destas ações, de comunicação entre a equipe e ainda sobre a postura e forma de lidar da equipe de incubação:

"A tentativa de autogestão algumas vezes se fortalece e outras se enfraquece. A equipe não tem uma postura e forma de lidar única com o grupo e isto fragiliza a incubação. Acredito que o maior exemplo é a autogestão do grupo, por mais que hajam estratégias há momentos que a autogestão é deixada de lado" (P1).

Esse relato evidencia que as dificuldades podem se relacionar aos membros e também a equipe e sua organização.

As possíveis dificuldades da equipe em relação a sua atuação nos EES podem ser originadas a partir do entendimento equivocado ou incompleto sobre a reabilitação psicossocial e o trabalho nos princípios de economia solidária. Nem sempre os conceitos de autonomia e autogestão estão claros para a equipe ${ }^{14}$. Sobre as dificuldades dos membros, Alcântara ${ }^{15}$, aponta para aspectos 
que merecem atenção. A pouca ou nenhuma escolaridade comum nestes indivíduos limitam seu crescimento e envolvimento significativamente. Incapacidade de raciocínios matemáticos, dificuldade de expressão oral são descritos pelas autoras como características dos usuários que, por estes motivos, deixam de opinar e de se expressarem perante o grupo de trabalho. Sustenta-se que estes atributos seriam importantes para um processo de gestão, por exemplo.

\section{Processos de produção}

$\mathrm{Na}$ economia solidária a relação entre autogestão e produção faz com que os modos de produção também sejam regidos por uma participação coletiva e, diferentemente do modelo hegemônico, a economia solidária apresenta como uma de suas características a posse coletiva dos meios de produção pelos indivíduos que compõem os $\mathrm{EES}^{6}$.

O poder horizontalizado intrínseco ao princípio de autogestão e decorrente da posse coletiva do capital responsabiliza os cooperados pelas suas práticas de produção, ou seja, pelo ritmo de trabalho, qualidade de produção, flexibilidade no fluxo de encomendas, aspectos que apareceram nos relatos dos participantes deste estudo.

Os participantes do estudo identificaram a existência de certa inflexibilidade dos membros perante a necessidade de aumento do ritmo de produção.

"O aumento repentino de produção por causa de encomendas que implica num aumento súbito do ritmo de trabalho que nem sempre é bem recebido pelos sócios" (P1).

O tempo e o ritmo de trabalho mesmo sendo flexíveis e decididos coletivamente podem desencadear pressão, o que pode gerar sofrimento nos trabalhadores como demonstrado no trabalho de Barfknecht et al. ${ }^{16}$.

Essa pressão nos cooperados possivelmente ocorre com mais intensidade quando há necessidade de aumento de produção para uma encomenda, por exemplo.

Os participantes identificaram o aumento da produtividade como um dos desafios dos EES que contam com a participação de usuários da saúde mental, como mostra o depoimento a seguir.

"Aumentar a produtividade para atender as grandes encomendas que estão chegando" (P3).

No tocante aos produtos, duas demandas apareceram. A primeira se relaciona à qualidade e é também mencionada como um desafio.

"Melhorar a qualidade do produto para não perder as vendas" (P3).

A segunda se refere à criação de novos produtos e novos designs e foi relatada por um dos participantes como uma necessidade.

"Precisamos de capacitação e criação de novos produtos com porta aberta para o mercado" (P4).

Quando o trabalho é um fim e não um meio, a qualidade do produto, assim como a criatividade para a elaboração dos mesmos, deve ser devidamente valorizada pelos cooperados. Como argumenta Alcantara ${ }^{15}$, a qualidade de um produto requer atenção, pois em um mercado competitivo esse fator pode determinar o consumo, ou no caso dos serviços, a contratação e melhores rendas.

A não rotatividade dos postos de trabalho é apontada por um dos participantes como uma dificuldade. Salienta a dificuldade dos usuários em assumir as várias etapas do processo de produção como mostra o depoimento a seguir:

"A principal dificuldade está relacionada à produção. O grupo demanda que todos os membros saibam operar qualquer etapa da produção das vassouras para que, além de possibilitar rotatividade, o grupo tenha fluidez para se organizar na produção quando os "buracos" aparecem, por exemplo, quando alguém falta ou algum problema gera um gargalo. Apesar de todos realmente conhecerem todas as etapas, os usuários dos serviços de saúde mental tendem a ficar mais fixados em alguma tarefa e tem mais dificuldade para assumir outro posto" (P3).

O mesmo sujeito fala sobre a oficina de capacitação como uma estratégia de enfrentamento dessas dificuldades.

"Fizemos uma oficina de rodízio de tarefas, passando o passo-a-passo o caminho da produção. Em cada etapa, eram levantadas as principais dificuldades, a relação com a etapa anterior e quais observações são necessárias para que fosse garantida a qualidade do produto. Assim, não só na etapa do acabamento mas durante todo o processo a questão da qualidade foi pautada. Todos puderam refletir junto e dialogar a respeito das dificuldades e qualidade esperada" (P3).

Pode-se verificar que esta foi uma estratégia que se relacionou com duas demandas apresentadas no EES: a necessidade de rotatividade nas atividades desenvolvidas pelos usuários e a qualidade de produção.

Os técnicos e/ou os profissionais que atuam nos EES 
com cooperados usuários vão percebendo a necessidade de incorporar novas questões à sua prática que se relacionam com os aspectos de mercado, qualidade da produção e estabelecimento de parcerias, por exemplo. Por outro lado, esses profissionais se deparam com a responsabilidade de fornecer autonomia aos cooperados ao invés de tomarem posse do saber e estabelecer relação vertical com os mesmos ${ }^{14}$.

Leite et al. ${ }^{17}$ apontam a necessidade de estabelecimento de uma relação horizontal entre cooperados e os profissionais atuantes nos EES e ao mesmo tempo a atenção desses últimos em relação aos aspectos de gerência e produção. Para tanto, os autores sugerem e identificam como importante o ensino prático sobre essas questões por meio de oficinas setoriais nas quais experiências de produção e comercialização, por exemplo, são viabilizadas.

Um EES com participação de usuário de serviço de saúde mental, que necessita de capacitações para a produção, pode apresentar esta demanda de forma constante ou permanente e pode ainda necessitar de auxílio para lidar com questões mais simples do trabalho como: assiduidade, pontualidade, regras e outros assuntos importantes ${ }^{18}$.

Apesar das problemáticas envolvidas os EES também apresentaram algumas facilidades, como mostram os depoimentos a seguir.

"O enorme mercado para alimentos (toda a população), aumento da demanda por produtos orgânicos; a tecnologia de produção ser relativamente simples" (P2)

"Facilidade de locomoção dos sócios, reconhecimento externo do trabalho deles, grande demanda de encomendas, adesão às atividades do EES" (P1)

Verifica-se então que as tecnologias de produção, a relação entre oferta e procura de mercado, a locomoção dos sócios, o reconhecimento externo do trabalho, são alguns dos pontos importantes que conduzem ou potencializam o sucesso do EES.

Progressos também são percebidos como pode-se verificar nos relatos a seguir.

"Há participação e construção coletiva de propostas de

\section{REFERÊNCIAS}

1. Santos BS, Rodríguez C. Para ampliar o cânone da produção. In: Santos BS. Produzir para viver: os caminhos da produção não capitalista. Rio de Janeiro: Civilização Brasileira; 2005. p.52-60. superação dos desafios. Por isso os resultados aparecem como organização da produção mais otimizada, maior produtividade (...)" (P3).

"Pude perceber estes progressos desde quando conheci o EES, há quatro anos, e como hoje eles avançaram em relação à qualidade dos produtos, organização, valores da economia solidária, espaço de comercialização" (P1).

$\mathrm{O}$ estudo de Tagliaferro ${ }^{12}$ mostra que progressos e avanços na produção podem ser percebidos ao longo do tempo pelos profissionais que acompanham os EES com participação de usuários da saúde mental. Esses progressos se relacionam com o aumento da iniciativa em aprender a confeccionar novos produtos e a iniciativa para executar tarefas. A criatividade e coordenação são também aprimoradas melhorando a qualidade dos produtos.

\section{CONCLUSÕES}

Os resultados evidenciam que as demandas, os desafios, as dificuldades e as oportunidades se relacionam com: o exercício da autogestão, os processos de produção, a interferência das subjetividades dos participantes dos EES no trabalho coletivo e aos apoios e parcerias estabelecidos.

Constituiu-se claramente como um destes desafios, a autogestão. Este princípio da economia solidária requer posturas e habilidades que não se apresentaram disponíveis em todos os usuários da saúde mental que participam dos EES pesquisados, requer ainda o apoio da equipe de incubação que deverá estar estruturada e organizada para lidar com esta demanda.

O estudo evidenciou a postura do técnico de incubação e equipe, além do manejo do ritmo de adaptação de cada cooperado, como essenciais para a possível resolubilidade das dificuldades e aproveitamento das facilidades para efetivar a reabilitação psicossocial dos usuários.

Espera-se que os resultados produzidos neste estudo contribuam para o processo de incubação de EES com USSM e sejam disparadores de outras pesquisas sobre a atuação de ITCPs com esta população.

2. Guimarães G. Incubadoras tecnológicas de cooperativas populares: contribuição para um modelo alternativo de geração de trabalho e renda. In: Singer P, Souza AR. A economia solidária no Brasil: a autogestão como resposta ao desemprego. 
Lussi IAO, et al. Incubadoras tecnológicas de cooperativas populares. Rev Ter Ocup Univ São Paulo. 2015 set.-dez.;26(3):345-54.

São Paulo: Contexto; 2003. p.111-22.

3. Culti MN. Economia solidária: incubadoras universitárias e processo educativo. Rev Proposta. 2007;31(111):16-22 [citado 10 mar. 2014]. Disponível em: http://www.fase.org.br/v2/ admin/anexos/acervo/1_nezilda.pdf.

4. Cortegoso AL, Shimbo I. Empreendimentos solidários, universidades, movimentos sociais e gestores públicos: articulação de esforços na promoção da economia solidária no Brasil de hoje. In: II Jornada Universitária Sobre Cooperativismo, Economía Solidaria y Procesos Asociativos, Montevidéo, Uruguai; 2005.

5. Singer P. A recente ressurreição da economia solidária no Brasil. In: Santos BS. Produzir para viver: os caminhos da produção não capitalista. Rio de Janeiro: Civilização Brasileira; 2005. p.81-7.

6. Singer P. Economia solidária: um modo de produção e distribuição. In: Singer P; Souza AR. A economia solidária no Brasil: a autogestão como resposta ao desemprego. São Paulo: Contexto; 2000. p.11-28.

7. Singer P. Alternativas da gestão social diante da crise do trabalho. In: Ricco EM, Raichelis R. Gestão social uma questão em debate. São Paulo: PUC-SP; 1999. p. 55-66.

8. Cortegoso AL, et al. Comportamentos ao incubar empreendimentos solidários: a descrição do fazer coletivo como referencial para o fazer de cada um. In: Cortegoso AL, Lucas MG. Psicologia e economia solidária: interfaces e perspectivas. São Paulo: Casa do Psicólogo; 2008. p.118-9.

9. Ballarin MLGS, Carvalho FB. Considerações acerca da reabilitação psicossocial: aspectos históricos, perspectivas e experiências. In: Cavalcanti A, Galvão C. Terapia ocupacional: fundamentação \& prática. Rio de Janeiro: Guanabara Koogan; 2007. p.162-70.

10. Saraceno B. Reabilitação psicossocial: uma estratégia para a passagem do milênio. In: Pitta A. Reabilitação psicossocial no Brasil. São Paulo: Hucitec; 1996. p.13-8.
11. Pinho KLR, et al. Apresentação. In: Pinho KLR, et al. Relatos de experiências de inclusão social pelo trabalho na saúde. São Carlos: Compacta gráfica editora; 2014. p. 9-11.

12. Tagliaferro P. Enfrentando desafios e construindo possibilidades: a experiência da equipe no processo de incubação de um empreendimento solidário formado por usuários de um CAPS [dissertação]. São Carlos: Universidade Federal de São Carlos; 2011. Disponível em: http://www. bdtd.ufscar.br/htdocs/tedeSimplificado//tde_busca/arquivo. php? $\operatorname{codArquivo}=4029$.

13. Bardin L. Análise de conteúdo. 5a ed. Lisboa: Edições 70; 2008.

14. Dakuzaku RY. A cooperativa como alternativa de trabalho à pessoa com deficiência. In: Souza $\mathrm{AR}$, et al. Uma outra economia é possível: Paul Singer e economia solidária. São Paulo: Contexto; 2003. p.239-43.

15. Alcântara LC. Economia solidária e oficinas de trabalho na saúde mental. In: Merhy EE, Amaral H. A reforma psiquiátrica no cotidiano II. São Paulo: Aderaldo e Rothschield; 2007. p.151-80.

16. Barfknecht KS, Merlo ARC, Nardi HC. Saúde mental e economia solidária: análise das relações de trabalho em uma cooperativa de confecção de Porto Alegre. Psicol Soc (Porto Alegre). 2006;18(2):54-61. http://dx.doi.org/10.1590/S010271822006000200008 .

17. Leite AS, et al. O programa Osasco solidária. In: Guerra A, Cazzuni D, Coelho R. Inclusão social com geração de ocupação e renda: uma cidade cada dia melhor. Osasco: Prefeitura Municipal; 2008. p.53-78.

18. Brasil. Ministério do Trabalho e do Emprego. Secretaria de Atenção à Saúde. Departamento de Ações Programáticas Estratégicas. Saúde mental e economia solidária: inclusão social pelo trabalho. Brasília (DF); 2005. Disponível em: www.cooperativismopopular.ufrj.br/saudemental/pdf/Saude Mental_Economia_Solidaria. 